\title{
Knowledge Attitude and Practices Related on Prevention of Mosquito Borne Diseases and Sanitation Conditions in a Salvadoran Urban Community
}

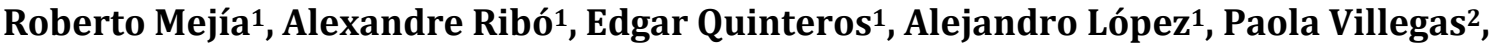 \\ Xavier F. Vela ${ }^{3}$, Ada Ruth Membreño² \\ ${ }^{1}$ National Institute of Health, Ministry of Health of El Salvador, San Salvador, El Salvador \\ ${ }^{2}$ University of El Salvador, San Salvador, El Salvador \\ ${ }^{3}$ Scientific Advisor-Salvadoran Renal Foundation, Bronx, NY, USA \\ Email: robertomejia1685@gmail.com
}

How to cite this paper: Mejía, R., Ribó, A., Quinteros, E., López, A., Villegas, P., Vela, X.F. and Membreño, A.R. (2016) Knowledge Attitude and Practices Related on Prevention of Mosquito Borne Diseases and Sanitation Conditions in a Salvadoran Urban Community. Occupational Diseases ane Environmental Medicine, 4, 83-102. http://dx.doi.org/10.4236/odem.2016.44010

Received: July 26, 2016

Accepted: September 24, 2016

Published: September 27, 2016

Copyright $\odot 2016$ by authors and Scientific Research Publishing Inc. This work is licensed under the Creative Commons Attribution International License (CC BY 4.0).

http://creativecommons.org/licenses/by/4.0/

cC) (i) Open Access

\begin{abstract}
Introduction: In El Salvador Mosquito Borne Diseases (MBDs) is a serious public health problem due to produce morbidity and mortality. They produce a high economic loss, which contributes to the collapse of the public health system. Over the years, the Salvadoran public health system has invested large amounts of resources to minimize the problem through campaigns against MBDs. Despite this, the population is still affected by diseases such as dengue, and more recently chikungunya and zika outbreaks. The aim of this study is to evaluate sanitation conditions variables and identify knowledge, attitudes, practices related to the prevention of MBDs. Methods: A cross-sectional survey about sanitation conditions and knowledge, attitudes and practices on prevention of MBDs of inhabitant's $\geq 15$ years from an urban community of a municipality with the highest number of cases reported in 2015 . Results: Majority of respondents (98.2\%) had direct supply of drinking water; however $96.4 \%$ of respondents were agreed that they had an inconsistent water supply. Regarding MBDs prevention respondents showed high acceptable knowledge (76.8\%), high favorable attitude (92.1\%) and an acceptable implementation of practices toward prevention reproduction of mosquitoes (58.5\%) and a poor implementation of practices to prevent mosquito bites (38.3\%). Conclusions: The findings revealed high acceptable knowledge about MBDs and a high favorable attitude regarding to prevent them, but also revealed a scarce implementation of prevention practices. The generalized storage of water on non-covered barrels because the inconsistent water supplies, can be source of proliferation of mosquitoes and therefore increases the risk
\end{abstract}


of transmission of MBDs. High population density of the community can magnify this risk. It is necessary to enhance education to promote better implementation of practices using the most common media together with the local health workers.

\section{Keywords}

Mosquito Borne Diseases, Knowledge Attitudes and Practices, WASH, Analytic Hierarchy Process, Dengue

\section{Introduction}

Mosquito borne diseases (MBDs) are diseases transmitted by mosquito bites and are spread worldwide, especially in the tropic and subtropical belts. These diseases are an important public health problem because they cause extensive morbidity and mortality especially in developing countries where poverty exacerbates population vulnerability. These diseases are a major economic burden within disease-endemic countries. Poor living conditions as lack of access to adequate housing, safe drinking water and sanitation, low access to health attention and the high adaptability of the mosquito vector to a broad fan of environmental conditions exacerbate the impact of MBDs in developing countries, especially among the poorest segments of the society. Dengue and malaria are the most important MBDs. Dengue is a viral disease produced by different types of arbovirus and transmitted mainly by Aedes aegypti and Aedes albopictus species, globally distributed and highly anthropophilic mosquitoes adaptable to different climatic conditions. Dengue produces around 390 million of infections each year of which 96 million manifests clinically with different levels of severity [1]. Malaria is produced by five species of parasitic protozoans and it is transmitted mainly by mosquitoes of genus Anopheles. Malaria is a leading cause of death and disease in many developing countries. The WHO estimates that in 2015, there were 214 million cases of malaria and 438,000 people died of malaria [2]. Other examples of hazardous MBDs are: yellow fever, lymphatic filariasis, West Nile fever, chikungunya and, recently, zika; which threat large regions of the world due to the globalization of travel and trade, unplanned urbanization and environmental challenges such as climate change contribute to expand quickly handoff MBDs. Chikungunya and zika are emerging in countries where they are previously unknown. Despite that zika and chikungunya do not produce high mortality rates; they produce high economic loss which contributes to the collapse of the public health system of the most developing countries. The optimal means of controlling any one of them are likely to be a combination of vector control, drugs, management of clinical illnesses and/or vaccines. However, there are no vaccines for most diseases and clinical management supposes elevated costs for health institutions, unaffordable for the most developing countries.

In El Salvador during the first half of the 20th century, a lot of resources were invested to mitigate the malaria that caused thousands of death [3] especially among the 
rural population, but efforts made by the Ministry of Health almost have mitigated it completely at the beginning of the 21 th century. In recent years, the main disease transmitted by mosquito in El Salvador has been dengue, however, large outbreaks of chikungunya and zika affected the population between 2014 and 2016 [4] [5]. These vector borne diseases affected almost all the country with major cities being the most affected.

Currently, the application of pesticides to control the adult mosquito supposes high economic costs to health institutions and possible environmental and human health concerns especially if used persistently. More effective ways are the preventive measures based on reproduction of mosquitoes. These are known as WASH (water, sanitation and hygiene) measures carried out at individual and community level and are focused on personal and housing protection and emphasized elimination of mosquito breeding sites in domestic areas. Although the Salvadoran Ministry of Health spent large amount of resources in both type of measures (massive pesticide application and communication with the public on risks and prevention measures), they were unsuccessful.

The final decision maker and executioner of these measures is the community, therefore a proper knowledge about these MBDs and proactivity at community level are key factors for obtaining successful results. Knowledge, Attitudes and Practices (KAP) surveys are effective tools to evaluate if preventive measures are being implemented properly in the community and to evaluate concerns regarding to its implementation. KAP studies are oriented to gather information on what people know, believe and do; in relation to a particular topic and are widely used to strengthen prevention campaigns in the field of vector-borne diseases [6]-[8].

The aim of this study was to evaluate WASH variables related to MBDs prevention in a homogeneous urban community. Selected community was located in Ilopango, one of the most heavily affected municipalities of San Salvador Metropolitan Area by outbreaks of dengue and chikungunya in 2015 [9]. We planned to identify knowledge, attitudes, practices related to the prevention of MBDs of the community inhabitants and sanitation conditions of the households.

\section{Methods}

\subsection{Study Area}

El Salvador is a developing country in the Pacific coast of Central America with the largest population density of continental America with $304 \mathrm{hab} / \mathrm{km}^{2}$ according to Ministry of Economy of El Salvador [10]. El Salvador is a small country with only 21,041 $\mathrm{km}^{2}$ and is bounded by Honduras to the north and east, by the Pacific Ocean to the south, and by Guatemala to the northwest (Figure 1(a)). El Salvador has a tropical climate with a dry season (November-April) and a wet season (May-October) [11] and it is affected periodically by tropical storms and hurricanes. As other Central-American countries, it is located in a high volcanic and seismically active area and has a rugged landscape heavily influenced by volcanic geomorphology. The highest density of population is concentered in metropolitan area of San Salvador, the capital of the 

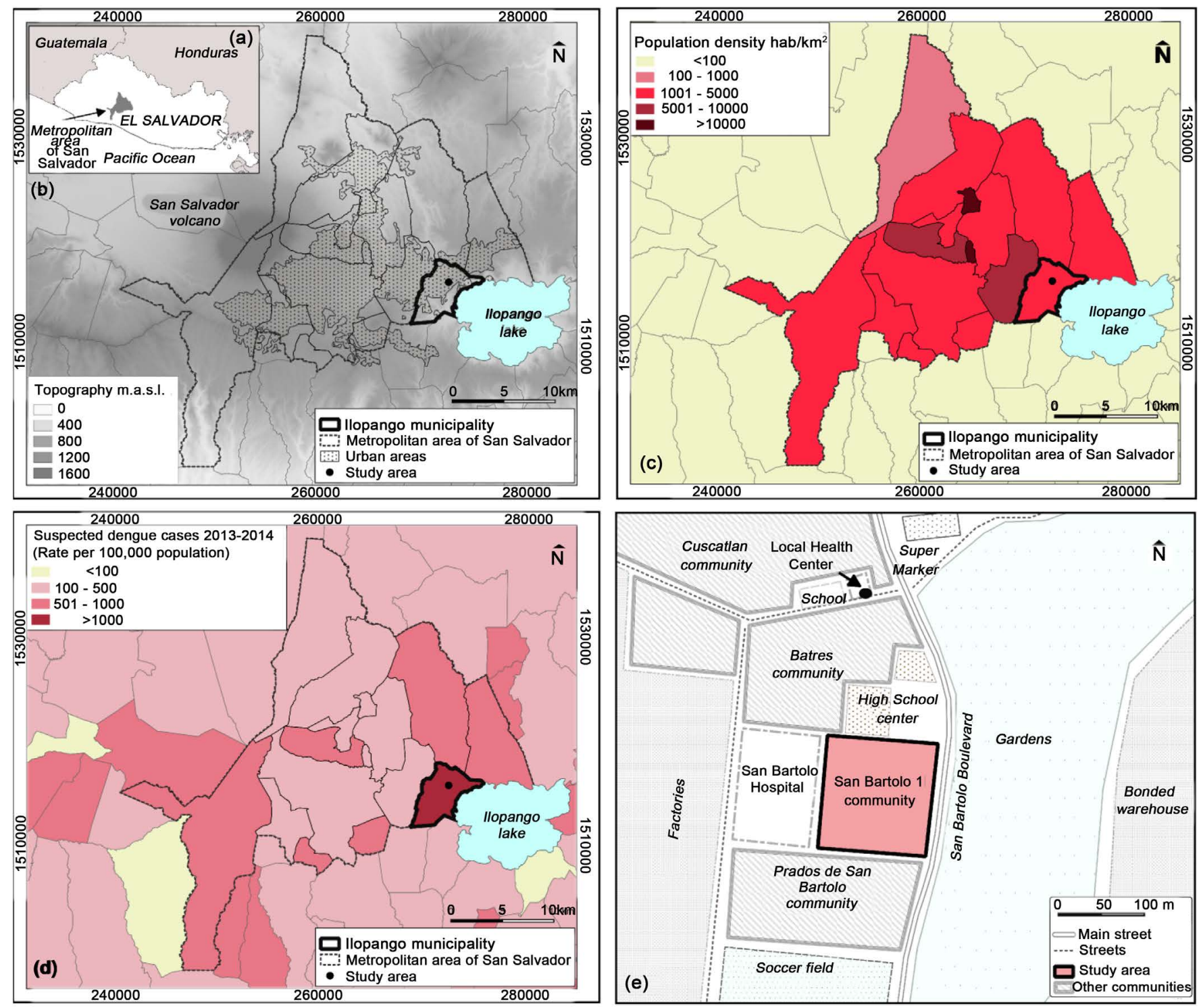

Figure 1. Location of the study area: (a) map of El Salvador, (b) metropolitan area of San Salvador and location of study area, (c) population density of metropolitan area of San Salvador, (d) rate of suspected cases of dengue 2013-2014 and (e) location of San Bartolo 1 community.

country, with $2881 \mathrm{hab} / \mathrm{km}^{2}$ [10] (Figure 1(b) and Figure 1(c)). Fourteen municipalities form the metropolitan Area of San Salvador. The most of them represent nonplaned urban areas. Urban slums with poor provided or without basic services locate next to extended neighborhoods of single-family houses with small courtyards only accessed through small alleyways, are common features of all metropolitan area. Especially this is the case in the crowded dormitory cities located in Ilopango, Soyapango, or Apopa municipalities that were the most affected by MBDs in recent years according to Ministry of Health records [9]. The present study was carried out in an urban community of Ilopango municipality (Figure 1(b)). Ilopango has a population density of 3221 $\mathrm{hab} / \mathrm{km}^{2}[10]$ and was the municipality with the most cases of MBDs (with 585 con- 
firmed cases by metropolitan hospitals and Ilopango presented the highest rate of suspected cases of dengue in 2013-2014 in San Salvador municipality) (Figure 1(d)) [9]. Urban community, called San Bartolo 1, is located at 634 m.a.s.l. and inhabited by working class families. San Bartolo 1 has surface of $1902 \mathrm{Ha}$ and has around 500 inhabitants therefore has local population density of 26,288 people per square kilometer (Figure 1(e)). Community is formed by several paved alleyways where small single family households $\left(45 \mathrm{~m}^{2}\right)$ are settled. In general, these homes are made by bricks and cement and commonly known as alleyway houses. These types of homes have only one floor and a small backyard. San Bartolo 1 is next to San Bartolo Hospital and has First-Level Health Care Facility located at a distance of $350 \mathrm{~m}$.

\subsection{Study Design and Population}

This work is a cross-sectional survey about WASH conditions, evaluating KAP of the community inhabitants towards the prevention of MBDs taking into account demographic variables and evaluating sanitation and water access conditions of households. The study was conducted from April to May 2015 in San Bartolo 1 community. Face-to-face interviews were performed directed to a representative of each household of $\geq 15$ years of age. Overall, the community consists of 177 households, whereby 110 household representatives were interviewed while the other 67 could not be sampled because of two reasons: the inhabitants were not found or they refused to participate.

\subsection{Survey Design}

The questionnaire was developed in Spanish following the recommendations proposed by WHO [12]. Questionnaire was divided in two sections: 1) demographic information (age, gender, education level, marital status, occupation and time living in the community) and questions about sanitation conditions such as access to drinking water, frequency of water supply, residential waste collection and final disposal of wastewater; 2) questions regarding on KAP of prevention of MBDs. All questions were close-ended except the participant's age, because are easy to standardize facilitate statistical analysis. Considered questions were formulated according the prevention recommendations of MBDs proposed by WHO and Salvadoran Ministry of Health [13]-[15] and some of them were stemmed from former KAP surveys related to MBDs prevention carried out in developing countries [16]-[20]. Then environmental health professors of University of El Salvador with KAP expertise were consulted to improve the validity of the questionnaire. Finally, the questionnaire was pre-tested with the aim to assess clarity and comprehensibility of the questions. All questions and the possible answers are listed in Table 1.

To find maximum number of household's representatives, the study was conducted during seven days, six labor days and one Sunday. Questionnaire was presented to household's representatives by interview technique, by a mixed couple of trained interviewers. Prior of the interviews an informed consent was read to explain the aim of this study. After that, only those individuals who showed their willingness to participate and 
Table 1. Questions asked to participants of this study.

Question

What is your gender?

How old are you?

What is the highest level of education you have completed?

What is your occupation?

Do you have access to water?

What is the frequency of water supply?

What is the garbage removal frequency?

Where do you dispose the wastewater?

\section{Possible answers}

Female/Male

Years

None/Primary and secondary/High School

College

Stay-at-home mothers/Worked in construction, maintenance or domestic employs/Students

\section{Water and sanitation conditions}

\section{Knowledge regarding to prevention of MBDs}

Which of the following diseases are transmitted by mosquitoes?

What is the mechanism of transmission of MBDs?

What is the time of day when mosquitoes are more likely to bite?

Which are mosquito breeding sites?

Which of these preventive measures do you consider more effective to avoid the reproduction of larvae and pupae?

Which of these measures do you consider more effective to prevent mosquito bites?
Dengue/Chagas/Yellow fever/Chikungunya/Malaria

Body fluids/water polluted/contaminated food/mosquito bite

At dawn/Noon/Before dusk/Afternoon and night/Only during night

Tires/hollow trees/on soil/gutters/in walls/on garbage

Apply the little dab

Eliminate stagnant water

Fumigate

Apply larvicide

Use of fishes on water containers

Covered water containers

Use of bed nets/Use of repellent/Use of insecticides/Covered water containers/Apply the little dab/Use of screens in window and doors

\section{Attitudes about prevention of MBDs}

Do you consider that preventive measures to reduce mosquitoes could avoid mosquito borne disease?

Are mosquito borne diseases serious problem?

Is it spraying the best method to reduce mosquitoes?

Is it Ministry of Health unique entity responsible

to reduce larvae of mosquitoes in your home?

Are you responsible to prevent spread of larvae in your home?
Strongly Agree ${ }^{\star}$ Agree*/Not sure/Disagree/Strongly disagree

Strongly Agree*/Agree*/Not sure/Disagree/Strongly disagree Strongly Agree/Agree/Not sure/Disagree*/Strongly disagree* Strongly Agree/Agree/Not sure/Disagree*/Strongly disagree* Strongly Agree /Agree $^{\star} /$ Not sure/Disagree/Strongly disagree

\section{Preventive measures against MBDs}

Which practices for preventing the mosquito breeding are you using?

Which practices for preventing the mosquito bites are you using?
Eliminate standing water/Use of larvicide/Wash water containers/Use of fishes in water containers

Use of insecticide/Use of repellent/Use of screens in window and doors/Use of fans/Use of bed nets

${ }^{\star}$ Favorable attitudes. 
agreed to sign the informed consent were selected to participate. In order to validate the questions about practices, household inspections were carried out at the same time to verify the application of preventive measure in each respondent's household following a guide that included two type of practices: practices to prevent of larvae and pupae spread (use of larvicide, wash water containers, use of fishes in water containers and covered water containers) and practices to prevent mosquito bites (use of insecticides, repellent, screens in window and doors, fans and/or bed nets).

At the end of each day a field supervisor together with all the interviewers reviewed the filled questionnaires to ensure the quality of data collected. Field supervisor digitalized all collected data by using EPI Info 7 software.

\subsection{Data Analysis}

Data analysis was carried out by an environmental researcher and a medical doctor and they were in close contact with field supervisor. Access to drinking water was evaluated by considering positive and negative answers. If access to water was positive, then we assessed if it was consistent (permanent) or inconsistent (irregular). Disposal grey water was evaluated considering if there was an adequate evacuation system (yes or no). Residential waste collection was evaluated considering if it was collected 3 or more times a week (correct) or less than 3 times a week (incorrect). Positive answers were scored as 1 while negatives as 0 .

Knowledge, attitudes and practices survey, regarding WASH strategies to prevent MBDs, were evaluated separately through different sets of questions. In order to evaluate the importance of each question, according to its contribution on determinant quantification and on risk mitigation of spreading MBDs, an analytic hierarchy process (AHP) was used [18]. AHP is a multi-criteria decision method that uses hierarchical structures to represent a problem and makes judgments based on experts to derive priority scales using pair wise comparison to evaluate the importance of each question. The hierarchy of the KAP questions is shown in Figure 2. The goal, level 1, is to evaluate KAP about WASH strategies to prevent MBDs. Level 2 is formed by the different factors considered in KAP studies: knowledge, attitudes and practices. Level 3 represents subfactors. Practices were split in 2 different subfactors: measures on eliminating breeding sites and measures on avoiding mosquito-bites. However, factors may not necessarily represent subfactors. Level 4 , is constituted by questions related to basic issues to prevent MBDs. These issues have a different impact on the prevention. Level 5 is formed by the population answers related to the level 4 questions. Thus, each alternative is described by the combination of the importance of the issue described in level 4 and the response of the community population to issues described in level 5.

A research expert judgment was obtained through a multidisciplinary group of professional profiles covering environmental health, psychiatry, epidemiology and biology. By consensus the expert group established the weight of each question by filling 4 pairwise comparison matrices, one for questions related to knowledge, another for attitudes and two for practices. The final weight of each question was obtained through the cal- 
Level

Level 2

Level 3

Level 4

Level 5

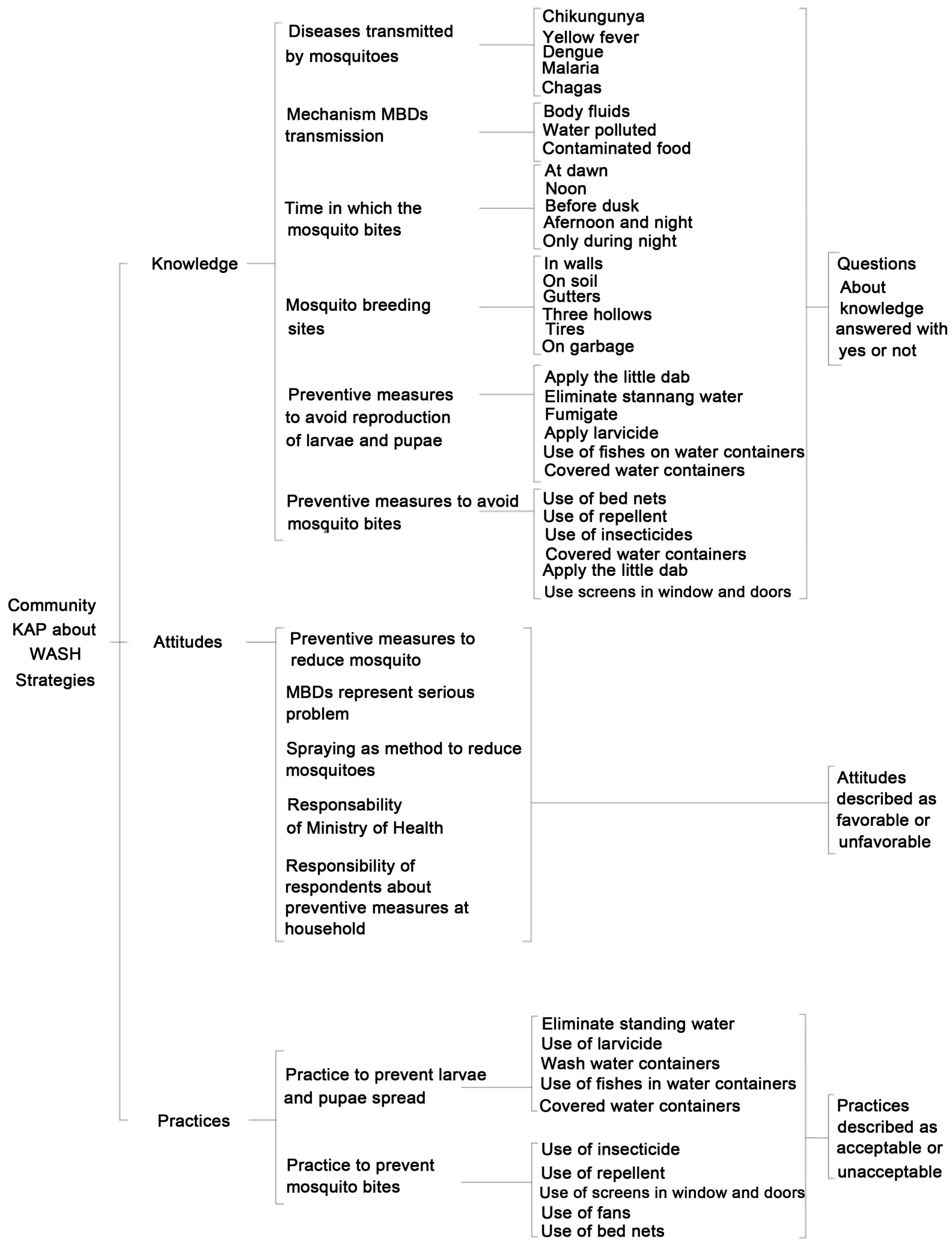

Figure 2. Hierarchy of social determinants of health of MBDs. 
culation of the eigenvector of each matrix. Finally, the consistency of the pairing process was checked through calculation of Consistence Index and Consistence Ratio [18]. If matrix results were not consistent the matrix was fine-tuned, by the expert group, following an iterative process.

First, level 5 answers were evaluated for each interviewed person using different criteria depending on if they are related to knowledge, attitude or practices.

To evaluate the knowledge related to a topic, the questionnaire presented a question related to that topic with different possible answers. Some of these answers were correct and some false. Respondent had to identify if different answers were true or false. If the respondent identified more than $50 \%$ of the answers correctly an acceptable knowledge related to that topic was considered and that question was scored by 1 . On the other hand, if less than $50 \%$ of the answers were not identified correctly it was considered that the respondent had an unacceptable knowledge and the question was scored by 0 .

Attitude answers were assessed using the Likert scale (strongly disagree, disagree, not sure, agree and strongly agree). In case of agreement was considered as a positive attitude these answers classified as agree or strongly agree with the topic were considered as favorable attitudes and scored with 1 while other classes were considered as a negative attitude and scored with 0 . In case of agreement was considered as a negative attitude, answers classified as strongly disagree or disagree were scored with 1 whereas other classes were scored with 0 .

Acceptable practices were scored by 1 and unacceptable was scored by 0 . Practices were assessed based on 10 basic preventive measures grouped into the following two categories: 1) Eliminating breeding sites and 2) Preventing of mosquito-bites. Acceptable practices were scored by 1 and unacceptable were scored by 0 .

Then, topics identified in level 4 were evaluated through the aggregation of the answer results. The community was classified as having adequate results related to a topic if the aggregated results showed that more than $50 \%$ of the interviewed household has chosen a correct answer in the case of knowledge, they showed a positive attitude or implemented the practices. Finally results for each factor presented in the level 2 (knowledge, attitude and practices) were obtained through the aggregation of weighted results obtained in level 4 .

Statistical analysis was performed by using Statistical Package Social Sciences 20.0 (SPSS). Each single KAP question was coded and evaluated according to the weight established with AHP. Additionally, comparisons of medians between sex, ages and educational level with the results of the KAP questions were conducted by using nonparametric tests: Mann Whitney and Kruskal-Wallis. Finally bivariate analysis was performed by Odd Ratio (OR).

\section{Results}

\subsection{Demographic Characteristics}

Table 1 presents the demographic characteristics of respondents obtained during the KAP household survey. 


\subsection{Water and Sanitation Conditions}

Almost all the houses have piped water supply (98.2\%). Water is supplied by ANDA, the national water company. ANDA supplies safe water. However, $96.4 \%$ of the respondents were agreed that they have an inconsistent water supply. Evidences for inconsistent water supply could be found during carrying out this survey: water containers for storing water were found in all visited homes. The majority of respondents (77.3\%) have regular waste collection three times a week and all of them have public wastewater systems.

\subsection{Knowledge, Attitudes and Practices}

Table 2 contains data related to knowledge about MBDs, Table 3 contains data about attitudes regarding MBDs prevention measures and Table 4 shows compiled data about practices to prevent reproduction of mosquitoes and mosquito bites. In the tables the questions of the KAP survey with the respective answers and the number of respondents and the proportion of respondents that choose each answer are listed. The weight according to the importance of each question obtained through the AHP is showed as well as the weighted percentage obtained of favorable answers to MBDs prevention. Finally, aggregates of the weighted percentages of respondents with an acceptable knowledge, favorable attitudes and practices, are presented in each table.

\subsubsection{Knowledge Regarding MBDs and Their Prevention}

The aggregated results show that the respondents have a high acceptable knowledge (76.8\%) regarding MBDs and their prevention (Table 2). Interviewed people show a good knowledge regarding the most important issues that are the preventive measures to avoid the reproduction of larvae and pupae and measures to prevent mosquito bites with $88.2 \%$ and $70.0 \%$ respectively. The respondents also obtained good results in other issues as places of mosquito breeding (95.5\%), mechanisms of transmission of MBDs (66.4\%) even about different MBDs (93.6\%). The worst results were obtained in the question related to the time in which the mosquito likely feeds/bites, only about $40.9 \%$ of the respondents gave an adequate answer.

Figure 3 presents sources of information about prevention of MBDs. Almost all participants $(89.1 \%)$ mentioned the TV as the main source about MBDs mitigation strategies. Most participants also obtained information from radio $(66.4 \%)$, health workers (61.4\%), schools (52.7\%) and newspapers (49.1\%).

\subsubsection{Attitudes toward Prevention of MBDs}

Table 3 shows that, in general, there had a favorable attitude regarding to prevention of MBDs with aggregate results $92.1 \%$. In order of relevance, the results show that the respondents are agree that it is within their responsibility to reduce larvae of mosquitoes at home and they agree that MBDs are serious health problems, obtaining 93.6\% and $98.2 \%$ respectively which are considered as favorable attitudes. The majority of interviewees agreed that preventive measures to reduce mosquitoes are important to avoid MBDs (96.4\%) and most of them disagree that the Ministry of Health is the 
Table 2. Sociodemographic profile of the participants.

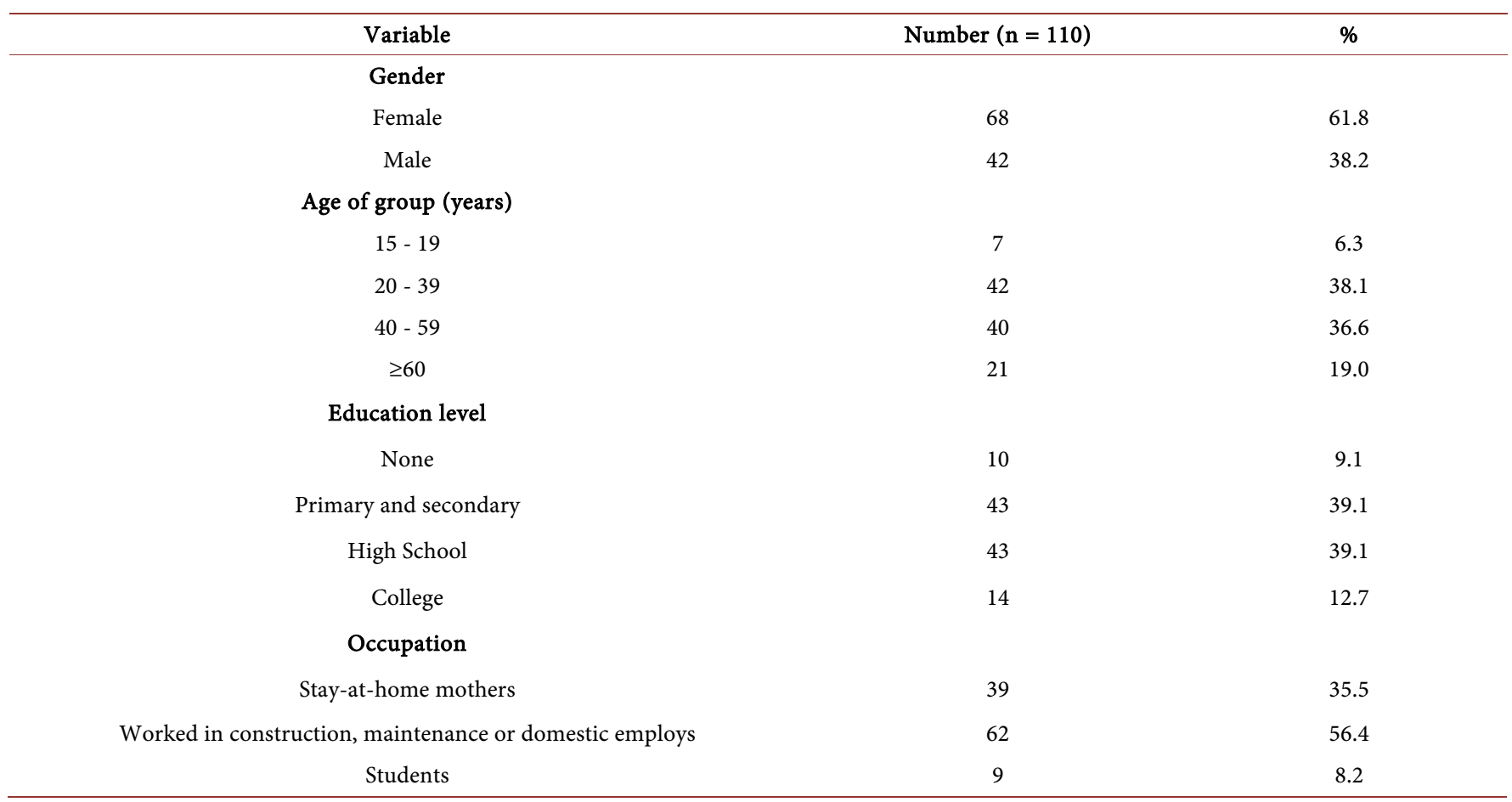

Table 3. Knowledge regarding to prevention of MBDs.

\begin{tabular}{|c|c|c|c|c|c|}
\hline \multirow{2}{*}{ Question } & \multirow{2}{*}{ Answers } & \multicolumn{2}{|c|}{$\mathrm{N}=110$} & \multirow{2}{*}{ Weight (\%) } & \multirow{2}{*}{$\begin{array}{c}\text { Weighted } \\
\text { favorable results (\%) }\end{array}$} \\
\hline & & Yes N (\%) & No $N(\%)$ & & \\
\hline Mechanism of transmission of MBDs: & $\begin{array}{l}\text { Body fluids/water polluted/ } \\
\text { contaminated food }\end{array}$ & $73(66.4)$ & $37(33.6)$ & 8.1 & 5.4 \\
\hline $\begin{array}{l}\text { Which of these are } \\
\text { mosquito breeding sites? }\end{array}$ & $\begin{array}{l}\text { Tires/Hollow trees/on soil/ } \\
\text { gutters/in walls/on garbage }\end{array}$ & $105(95.5)$ & $5(4.5)$ & 10.8 & 10.3 \\
\hline $\begin{array}{l}\text { Which of these measures do you consider } \\
\text { more effective to prevent mosquito bites? }\end{array}$ & $\begin{array}{l}\text { Use of bed nets } \\
\text { Use of repellent } \\
\text { Use of insecticides } \\
\text { Covered water containers } \\
\text { Apply the little dab } \\
\text { Use of screens in } \\
\text { window and doors }\end{array}$ & $77(70.0)$ & $33(30.0)$ & 34.6 & 24.2 \\
\hline Aggregation & & & & 100 & 76.8 \\
\hline
\end{tabular}




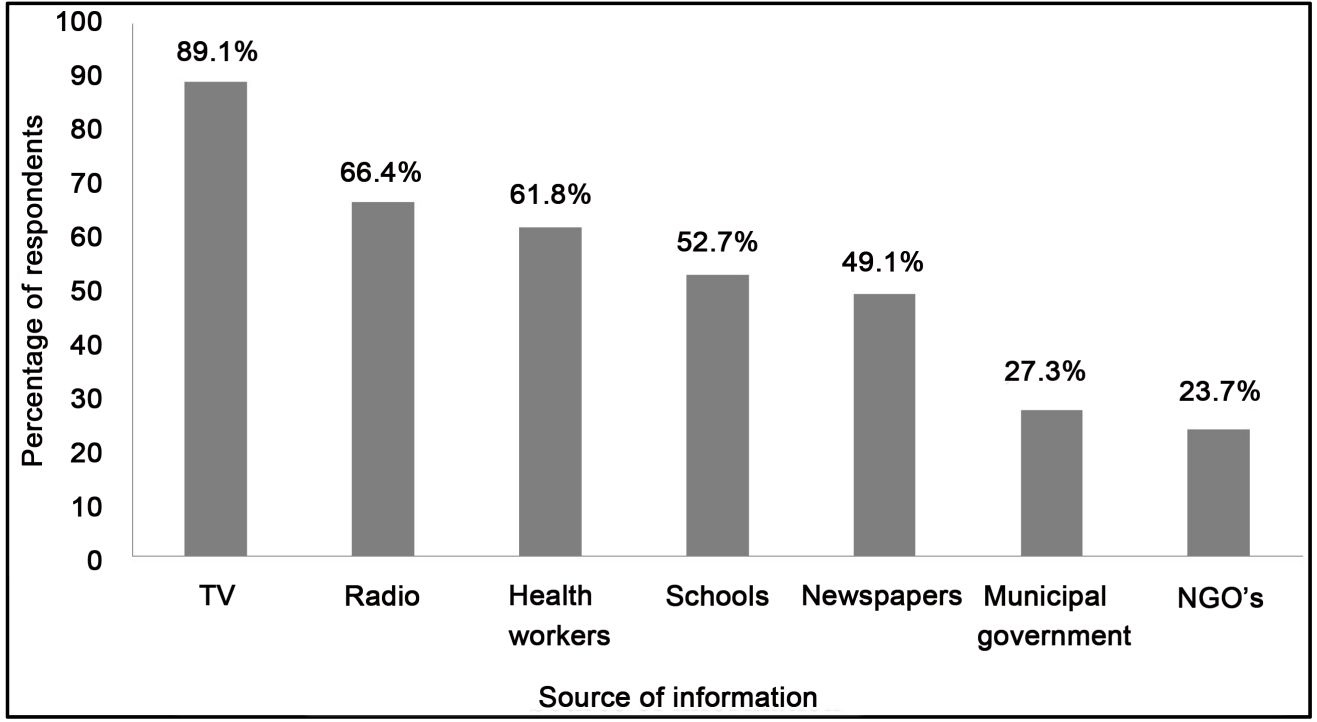

Figure 3. Source of information on prevention of MBDs.

Table 4. Attitudes about prevention of MBDs.

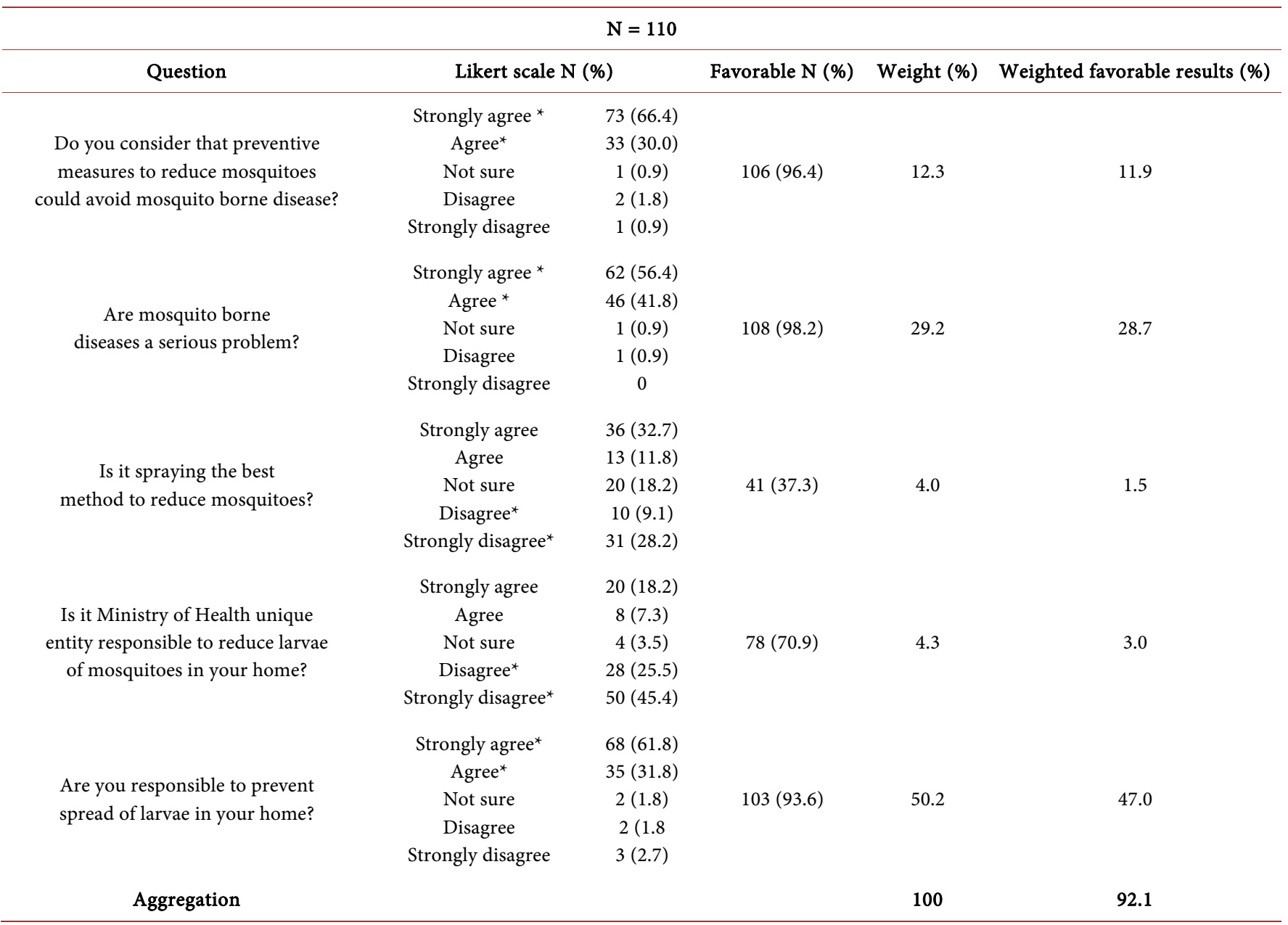

*Favorable attitudes. 
unique entity responsible for domiciliary reduction of larvae of mosquitoes (70.9\%) which is considered a favorable attitude, too. The only unfavorable attitude was that a majority of respondents $(62.7 \%)$ have the perception that spraying pesticides is the best method to reduce mosquitoes.

\subsubsection{Practices toward Prevention of MBDs}

As shown in Table 5, the surveyed population showed an acceptable implementation of practices toward the prevention of mosquito reproduction (58.5\%) and a poor implementation to prevent mosquito bites (38.3\%).Regarding the most important practices to prevent reproduction of mosquitoes according to the weight factor, almost all respondents eliminate standing water $(89.1 \%)$ and wash the water containers $(84.5 \%)$ but only few cover water containers (23.6\%). Secondary practices as application of larvicides or use of fishes in water containers are only slightly applied with $39.1 \%$ and $4.5 \%$ respectively. Regarding to mosquito bite prevention practices with a higher weight factor, the majority use bed nets $(62.7 \%)$ but only a low percentage of the interviewed households use screens in windows and doors (5.5\%). Regarding other practices of lower importance, most of the respondents used fans to prevent mosquito bites (73.6\%) but other measures, as application of insecticides and repellents, are poorly used (35.5\% and $33.6 \%$ respectively).

\subsection{Comparison between the Groups or Variables}

There were not statistical differences across gender, ages and educational level with KAP variables. Therefore there are no statistical significant differences between of populations and independent variables regarding to KAP.

Table 5. Preventive measures against MBDs.

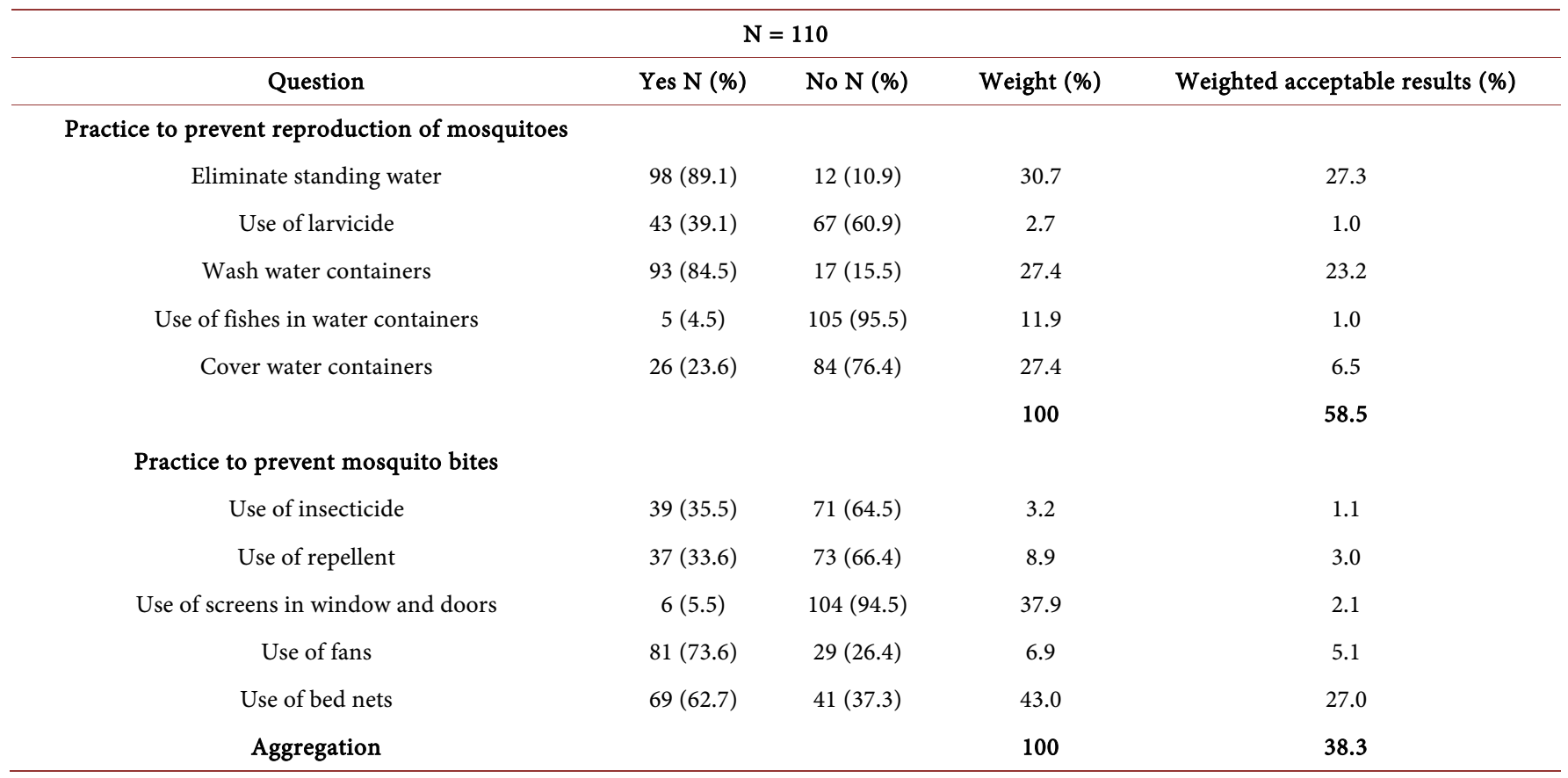




\section{Discussion}

The study revealed appropriate sanitation conditions of the community; it also had direct supply of drinking water although irregular and interrupted. Interviewed household's representatives showed a good knowledge and attitudes regarding to the prevention of MBDs, but the population had a poor implementation of practices, especially those related to avoid mosquito bites. Poor practices were not related to any pattern related to sex or age.

Interruptions of water supply are common in El Salvador, according to a FESAL survey only $60 \%$ - 70\% of households of San Salvador Department obtains water supply 7 days per week and more than 4 hours per day [19]. Households store water in barrels of $210-220 \mathrm{~L}$ to prevent inconsistencies of water supply. These barrels are a potential source of mosquito breeding sites if preventive measures are not performed as shown in other studies in other developing countries [21] [22].

The surveyed people showed a good knowledge about MBDs including advanced topics like different types of vector borne diseases. Positive attitudes on disease prevention were found, too. The only handicap, observed as a negative attitude, was the perception of the majority of the population that the use of pesticides is regarded as the best method to prevent MBDs. The authors identify this attitude as negative because this intervention could be useful in short term at local level but recent widespread outbreaks of MBDs demonstrate another pattern (i.e. dengue, chikungunya and zika). There is no clear evidence in scientific literature for the effectiveness of per domestic space spraying in the case of Aedes-borne diseases transmission [20]. Moreover massive widespread use of pesticides can be a threat to both human and environmental health and represented a regular investment of great amount of resources for the Ministry of Health of El Salvador in 2014 [9].

These high levels of knowledge and positive attitudes can be related especially to the diffusion of information about MBDs in TV and radio mainly carried out by the Ministry of Health. Similar results were found in other developing countries [17]. Moreover, it is necessary to highlight that the respondents have noted the importance of health workers on the prevention of MBDs. Thus, the communicative strategy of the Ministry of Health had a positive impact to this community. On the other hand, in the case of an outbreak, the information should be carefully evaluated because it can lead to panic or other reactions. For example, during the zika outbreak in 2015-2016 several Latin American countries, among them El Salvador, recommended women not to get pregnant, because of the possible association between zika and microcephaly identified in Brazil and recently in Colombia [23]-[25]. This recommendation is unrealistic in a country where women cannot decide the outcome of their fertility-especially in the rural areas. Males should also be included in this recommendation since new evidence suggest that the zika virus can be transmitted sexually [26].

In the most cases this information was spread through sensationalist way and produced a debate on Latin American women's right to access safe abortions and the enforcement of restrictive laws in the region. Until this day, in El Salvador, there are no 
policies that allow women to undergo safe abortion practices.

Practices otherwise showed poorer results than knowledge and attitudes. Almost nobody carried out basic preventative measures such as covering water containers and only few carried out basic practices to avoid mosquito bites like use of repellent, insecticides and use of screen in window and doors. The presence of Aedes aegipty and Aedes albopictus mosquitoes is directly influenced by the availability of water-holding containers for oviposition and larval development. Taking into account that garbage in the streets is scarce due the regular waste collection, the main breeding habitats are the barrels for tap water storage. Almost all households have one or more non covered water containers in the yard because of the irregular water supply. Non covered containers can favor mixing of tap water and rain water which improve tap water as breeding habitat as suggest Getacheu et al. [27]. Thus this community present environmental characteristic required for the proliferation of Aedes aegipty and Aedes albopictus. These conditions may be magnified by high density of population and the horizontal distribution of households. This is not only a particular situation of this community, according the high larval indices recorded recently in the region. A house index (HI) of $8-11$ calculated for the whole country and a HI of 18 - 32 recorded for San Salvador department by MINSAL in the first 31 epidemiological weeks in 2015 [28]. However larval indices are a poor indication of mosquito adult infestation, PAHO proposes a $\mathrm{HI}>5$ as a high risk for dengue transmission [29]. The high mosquito proliferation complemented by the high human population density of the community increases the chances of stable transmission cycles between infected and susceptible persons. Hence the community presents a high risk of transmission of MBDs, especially these transmitted by Aedes aegipty and Aedes albopictus like dengue, zika and chikungunya.

Small neighborhood stores and a closer supermarket are well provided by of anti-mosquito products such as repellents or household insecticides; however, these products are costly what can limit their use. Mulla et al. showed that, proportionally, the costs of household anti-mosquitoes products are higher in developing countries than compared with developed countries [30]. Screens on windows and doors protect households 24-hours a day against mosquito vectors as malaria, dengue or filariasis [31]-[33] as well as the house fly which spreads diarrheal diseases, that are ones of the most important health problems in El Salvador, too. Windows screens were considered as one of the significant steps in mitigation of malaria in industrializing nations in the early 20th century [34].

Limitation of this study includes the exclusion of better inquiry on explanation about some questions in the knowledge and attitudes sections. Participants may have felt pressured to give answers they felt were socially appropriate. The multidisciplinary group would have been improved adding other professional profiles in order to obtain better estimation of the weight of each question. Despite these limitations, the findings of the present survey have important implications to understand the behavior of people and the weaknesses that expose to the people to MBDs.

Efficient and sustainable program of prevention of MBDs must involve governmen- 
tal stakeholders, who should plan and oversaw the program, and community, who helped execute control measures and permitted access to their property as showed before [35] [36]. Following a similar methodology like the National Malaria Program of El Salvador, in which the community had an essential role through a volunteer collaborators network [37].

In the present community, according to the KAP results and the hierarchy analysis of the importance, an intervention to prevent Aedes infestation should be focused on preventive practices against both immature and adult mosquitoes and to strengthen the importance of household practices to prevent MBDs. Governmental institutions should to promote covering water containers and use of windows and door screens as carried out by Garcia-Betancourt et al. [38]. Health officials should explain this practice to the community through workshops; features of the water containers should be evaluated and local manufactures should be involved to produce water container covers. This intervention can be complemented by promoting other alternatives like the application of little dab known in Spanish as la untadita and to evaluate the introduction of local larvivorous fishes as an alternative to larvicide application. However some studies identified larvavorous fishes as a useful method to eliminate mosquitoes larvae cheaper than larvicide [39] [40], there is no evidence to demonstrate any community effectiveness of this method as a single agent [41]. Moreover, viability of this implementation has to be evaluated considering the presence of chlorine in water because some species do not tolerate chlorine levels of treated drinking water [42]. Finally, the workshop should consider rational use of household pesticides and repellents taking into account the possible impact to human health of these products and giving priority to natural products and the less harming options. Gang violence context in El Salvador could be a handicap to an intervention. The gangsters threaten the population of the communities and blackmail them. As shown by UNDP fear makes the inhabitants of the community distrust on each other and, therefore it is difficult to promote any intervention in the communities, especially among young people.

\section{Conclusion}

The analysis carried out in the present study yielded a clear snapshot of the status of MBDs knowledge, attitudes, and practice in April to May 2015 in San Bartolo 1 community. The findings revealed high acceptable knowledge about MBDs, a high favorable attitude regarding to prevent them and a scarce of implementation of practices to prevent them. Results showed the general conformism about the spraying of pesticides such as the best method to control of adult mosquito. Additionally, the storage of water on non-covered water containers because of the irregular water supply is a generalized practice. Containers filled full of clean waters are common breeding sites for Aedes albopictus and Aedes aegipty mosquitoes and therefore there is a high risk of Aedesborne diseases transmission that is magnified by the high population density of the community. It is necessary to enhance education to promote implementation of preventive practices, especially the simplest and efficient such as use of water container 
covers and use window screens. Common media such as TV and Radio, together with local health workers are the most useful channels for spreading the information related to prevention practices.

\section{Acknowledgements}

This work was supported by the grants of Spanish Agency for International Development Cooperation (AECID, the Spanish acronym) and National Institute of Health, Ministry of Health of El Salvador. We are indebted to Lic. Orbelina Delgado for her invaluable help in fieldwork. We want to thank professor Engelbert Niehaus and Jörg Rapp from University of Koblenz Landau of Germany and Dr. Ernesto B. Pleités from National institute of Health for their suggestions about the analysis of the results of KAP.

\section{References}

[1] Bhatt, S., Gething, P.W., Brady, O.J., Messina, J.P., Farlow, A.W., Moyes, C.L., et al. (2013) The Global Distribution and Burden of Dengue. Nature, 496, 504-507. http://dx.doi.org/10.1038/nature12060

[2] WHO (2015) World Malaria Report 2015. http://www.who.int/malaria/publications/world-malaria-report-2015/report/en/

[3] Sutter, V. and Zuniga, H. (1942) A Malaria Survey of El Salvador, Central America. The American Journal of Tropical Medicine and Hygiene, 22, 387-398.

[4] ISAT (2001) Diagnóstico Situacional del uso de DDT y el control de la malaria. México y Centroamérica.

http://www3.cec.org/islandora/es/item/1755-diagnostico-situacional-del-uso-de-ddt-y-el-c ontrol-de-la-malaria-es.pdf

[5] The Lancet (2016) Zika Virus: A New Global Threat for 2016. The Lancet, 387, 96. http://dx.doi.org/10.1016/S0140-6736(16)00014-3

[6] Moro M.L., Gagliotti C., Silvi G., Angelini R., Sambri V., Rezza G., et al. (2010) Knowledge, Attitudes and Practices Survey after an Outbreak of Chikungunya Infections. International Health, 2, 223-227. http://dx.doi.org/10.1016/j.inhe.2010.07.003

[7] Nazareth, T., Teodósio, R., Porto, G., Gonçalves, L., Seixas, G., Silva, A.C., et al. (2014) Strengthening the Perception-Assessment Tools for Dengue Prevention: A Cross-Sectional Survey in a Temperate Region (Madeira, Portugal). BMC Public Health, 14, 39. http://dx.doi.org/10.1186/1471-2458-14-39

[8] Shuaib, F., Todd, D., Campbell-Stennett, D., Ehiri, J. and Jolly, P.E. (2010) Knowledge, Attitudes and Practices Regarding Dengue Infection in Westmoreland, Jamaica. West Indian Medical Journal, 59, 139-146.

[9] MINSAL (2015) Sistema Nacional de Salud MorbiMortalidad + Estadisticas Vitales (SIMMOW). http://simmow.salud.gob.sv/

[10] MINEC (2015) Encuesta de Hogares de Propósitos Múltiples 2014. http://www.digestyc.gob.sv/index.php/temas/des/ehpm/publicaciones-ehpm.html

[11] The World Bank Group (2016) Climate Change Knowledge Portal. http://sdwebx.worldbank.org/climateportal/index.cfm?page=country historical climate\&T hisRegion $=$ Latin $\% 20$ America $\&$ ThisCcode $=$ SLV\#

[12] WHO (2008) Advocacy, Communication and Social Mobilization for TB Control: A Guide 
to Developing Knowledge, Attitude and Practice Surveys. World Health Organization, Stop TB Partnership, Geneva. http://whqlibdoc.who.int/publications/2008/9789241596176 eng.pdf

[13] MINSAL (2014) Lineamientos técnicos para la prevención y control de la fiebre Chikungunya.

http://www.salud.gob.sv/archivos/pdf/promocion salud/material educativo/campana chik ungunya/Lineamientos Chikungunya2014.pdf

[14] WHO (2009) Dengue Guidelines for Diagnosis, Treatment, Prevention and Control. Geneva, 147 p. http://apps.who.int/iris/bitstream/10665/44188/1/9789241547871 eng.pdf

[15] PAHO (2016) Malaria Prevention, Surveillance and Control. http://www1.paho.org/hq/dmdocuments/2009/manual malaria.pdf

[16] Dhimal, M., Aryal, K.K., Dhimal, M.L., Gautam, I., Singh, S.P., Bhusal, C.L., et al. (2014) Knowledge, Attitude and Practice Regarding Dengue Fever among the Healthy Population of Highland and Lowland Communities in Central Nepal. PLOS ONE, 9, e102028. http://dx.doi.org/10.1371/journal.pone.0102028

[17] Egedus, V.L., Ortega, J.M. and Obando, A.A. (2014) Knowledge, Perceptions, and Practices with Respect to the Prevention of Dengue in a Mid-Pacific Coastal Village of Costa Rica. Revistade Biología Tropical, 62, 859-867. http://dx.doi.org/10.15517/rbt.v62i3.14065

[18] Mayxay, M., Cui, W., Thammavong, S., Khensakhou, K., Vongxay, V., Inthasoum, L., et al. (2013) Dengue in Peri-Urban Pak-Ngum District, Vientiane Capital of Laos: A Community Survey on Knowledge, Attitudes and Practices. BMC Public Health, 13, 434. http://dx.doi.org/10.1186/1471-2458-13-434

[19] Esu, E., Lenhart, A., Smith, L. and Horstick, O. (2010) Effectiveness of Peridomestic Space Spraying with Insecticide on Dengue Transmission: Systematic Review. Tropical Medicine and International Health, 15, 619-631. http://doi.wiley.com/10.1111/j.1365-3156.2010.02489.x http://dx.doi.org/10.1111/j.1365-3156.2010.02489.x

[20] Nalongsack, S., Yoshida, Y., Morita, S., Sosouphanh, K. and Sakamoto, J. (2009) Knowledge, Attitude and Practice Regarding Dengue among People in Pakse, Laos. Nagoya Journal of Medical Science, 71, 29-37.

[21] Saaty, R.W. (1987) The Analytic Hierarchy Process-What It Is and How It Is Used. Mathematical Model, 9, 161-176. http://dx.doi.org/10.1016/0270-0255(87)90473-8

[22] Asociación Demográfica Salvadoreña (2016) Encuesta Nacional de Salud Familiar FESAL 2008. http://www.fesal.org.sv/

[23] Nature (2016) First Zika-Linked Birth Defects Detected in Colombia: Nature News \& Comment. http://dx.doi.org/10.1038/nature.2016.19502

[24] Mlakar, J., Korva, M., Tul, N., Popović, M., Poljšak-Prijatelj, M., Mraz, J., et al. (2016) Zika Virus Associated with Microcephaly. New England Journal of Medicine, 374, 951-958. http://www.nejm.org/doi/full/10.1056/NEJMoa1600651 http://dx.doi.org/10.1056/NEJMoa1600651

[25] Brasil, P, Pereira Jr., J.P., Raja Gabaglia, C., Damasceno, L., Wakimoto, M., Ribeiro Nogueira, R.M., et al. (2013) Zika Virus Infection in Pregnant Women in Rio de JaneiroPreliminary Report. New England Journal of Medicine. http://www.nejm.org/doi/10.1056/NEJMoa1602412

[26] CDC (2016) Zika and Sexual Transmission, Zika Virus. http://www.cdc.gov/zika/transmission/sexual-transmission.html

[27] Getachew, D., Tekie, H., Gebre-Michael, T., Balkew, M. and Mesfin, A. (2015) Breeding 
Sites of Aedes aegypti: Potential Dengue Vectors in Dire Dawa, East Ethiopia. Interdisciplinary Perspectives on Infectious Diseases, 2015, Article ID: 706276.

http://dx.doi.org/10.1155/2015/706276

[28] MINSAL (2015) Boletín Epidemiológico Ministerio de Salud.

http://www.paho.org/els/index.php?option=com content\&view=article\&id=483:boletin-epi demiologico-ministerio-salud

[29] PAHO (1994) Dengue and Dengue Hemorrhagic Fever in the Americas. Guidelines for Prevention and Control.

http://apps.who.int/bookorders/anglais/detart1.jsp? codlan=1\&codcol=61\&codcch $=548$

[30] Mulla, M.S., Thavara, U., Tawatsin, A., Kong-Ngamsuk, W. and Chompoosri, J. (2001) Mosquito Burden and Impact on the Poor: Measures and Costs for Personal Protection in Some Communities in Thailand. Journal of the American Mosquito Control Association, 17, 153-159.

[31] Ogoma, S.B., Lweitoijera, D.W., Ngonyani, H., Furer, B., Russell, T.L., Mukabana, W.R., et al. (2010) Screening Mosquito House Entry Points as a Potential Method for Integrated Control of Endophagic Filariasis, Arbovirus and Malaria Vectors. PLOS Neglected Tropical Diseases, 4, e773. http://dx.doi.org/10.1371/journal.pntd.0000773

[32] Ogoma, S.B., Kannady, K., Sikulu, M., Chaki, P.P., Govella, N.J., Mukabana, W.R., et al. (2009) Window Screening, Ceilings and Closed Eaves as Sustainable Ways to Control Malaria in Dar es Salaam, Tanzania. Malaria Journal, 8, 221. http://dx.doi.org/10.1186/1475-2875-8-221

[33] Thammapalo, S., Meksawi, S. and Chongsuvivatwong, V. (2012) Effectiveness of Space Spraying on the Transmission of Dengue/Dengue Hemorrhagic Fever (DF/DHF) in an Urban Area of Southern Thailand. Journal of Tropical Medicine, 2012, Article ID: 652564. http://dx.doi.org/10.1155/2012/652564

[34] Budiansky, S. (2002) Creatures of Our Own Making. Science, 298, 80-86. http://dx.doi.org/10.1126/science.298.5591.80

[35] Gubler, D.J. and Clark, G.G. (1996) Community Involvement in the Control of Aedes aegypti. Acta Tropica, 61, 169-179. http://dx.doi.org/10.1016/0001-706X(95)00103-L

[36] Pérez, D., Lefèvre, P., Sánchez, L., Sánchez, L.M., Boelaert, M., Kourí, G., et al. (2007) Community Participation in Aedes aegypti Control: A Sociological Perspective on Five Years of Research in the Health Area "26 de Julio", Havana, Cuba: Community Participation in Aedes aegypti. Tropical Medicine and International Health, 12, 664-672. http://dx.doi.org/10.1111/j.1365-3156.2007.01833.x

[37] PATH (2016)Malaria Elimination in el Salvador. A Historical and Epidemiological Perspective.

http://www.makingmalariahistory.org/wp-content/uploads/2016/02/NOT-FOR-EXTERNA L-CIRCULATION-PATH-ElSalvador-Malaria-Elimination.pdf

[38] García-Betancourt, T., González-Uribe, C., Quintero, J. and Carrasquilla, G. (2014) Ecobiosocial Community Intervention for Improved Aedes aegypti Control Using Water Container Covers to Prevent Dengue: Lessons Learned from Girardot Colombia. EcoHealth, 11, 434-438. http://dx.doi.org/10.1007/s10393-014-0953-8

[39] Kusumawathie, P.H.D., Wickremasinghe, A.R., Karunaweera, N.D. and Wijeyaratne, M.J.S. (2008) Costs and Effectiveness of Application of Poecilia reticulata (Guppy) and Temephos in Anopheline Mosquito Control in River Basins below the Major Dams of Sri Lanka. Transactions of the Royal Society of Tropical Medicine and Hygiene, 102, 705-711. http://dx.doi.org/10.1016/j.trstmh.2008.03.013 
[40] Seng, C.M., Setha, T., Nealon, J., Socheat, D., Chantha, N. and Nathan, M.B. (2008) Community-Based Use of the Larvivorous Fish Poecilia reticulata to Control the Dengue Vector Aedes aegypti in Domestic Water Storage Containers in Rural Cambodia. Journal of Vector Ecology, 33, 139-144. http://dx.doi.org/10.3376/1081-1710(2008)33[139:CUOTLF]2.0.CO;2

[41] Elas, M., Romero, E., González, A., Alvarado, J., Navascues, V., Núnez, A., et al. (2004) Ensayo para evaluar la utilidad del género Poeciliasp. Como biocontrolador de los estadios acuáticos del Aedes Aegipti. Ministerio de Salud Públic a y Asistencia Social, CHANGEAED-USAID. http://pdf.usaid.gov/pdf docs/Pnadc159.pdf

[42] UNDP (2013) Sección 4: Desaprovechar la riqueza: Inmigración y violencia. En: Informe sobre Desarrollo Humano 2013 Imaginar un nuevo país Hacerlo posible, San Salvador, El Salvador, 202-227.

\section{Submit or recommend next manuscript to SCIRP and we will provide best service} for you:

Accepting pre-submission inquiries through Email, Facebook, LinkedIn, Twitter, etc. A wide selection of journals (inclusive of 9 subjects, more than 200 journals)

Providing 24-hour high-quality service

User-friendly online submission system

Fair and swift peer-review system

Efficient typesetting and proofreading procedure

Display of the result of downloads and visits, as well as the number of cited articles

Maximum dissemination of your research work

Submit your manuscript at: http://papersubmission.scirp.org/

Or contact odem@scirp.org 